\title{
The Internalized Stigma of Mental Illness: Cross-Cultural Adaptation and Psychometric Properties of the Portuguese Version of the ISMI Scale
}

\author{
Sandra E. H. Oliveira • Francisco G. Esteves • \\ Edgar G. Pereira $\cdot$ Marina Carvalho $\cdot$ \\ Jennifer E. Boyd
}

Received: 11 November 2013/Accepted: 13 January 2015/Published online: 23 January 2015

(C) Springer Science+Business Media New York 2015

\begin{abstract}
This study examined the psychometric properties of the Portuguese version of the ISMI scale in a sample of 253 adult psychiatric outpatients. The exploratory factor analysis replicated the five factor structure of the scale. The results revealed good internal consistency. Criterion-related validity supported the variability in response to stigma across clinical diagnoses. Thus, the Portuguese version of the ISMI scale can be considered appropriate to measure and differentiate between stigmatization experiences. Also, in order to design more focused approaches aimed to reduce the negative effects of internalized stigma, its use in institutional and in community-based mental health services is recommended.
\end{abstract}

Keywords ISMI $\cdot$ Self-stigma $\cdot$ Portuguese $\cdot$ Mental disorders $\cdot$ Diagnosis

\section{Introduction}

Living with a mental illness is an experience that is not limited to the symptoms of the disorder. People with mental illness often face an additional problem: public stigma (Rüsch et al. 2006).

As sustained by the literature (Livingston and Boyd 2010), three levels of stigma towards mental illness must be differentiated: social stigma (also known as public or enacted stigma), structural stigma (or institutional stigma) and internalized stigma (also referred as self-stigma). Whereas social stigma occurs as a result of negative stereotypes, prejudices and discrimination toward psychiatric patients, (Corrigan 2000; Watson and Larson 2006) causing the "us" versus "them" effect (Link et al. 2004), structural stigma involves institutional policies and procedures that limit people's access to their rights (Corrigan et al. 2005). Either resulting from social, structural stigma, or both, research has consistently demonstrated the impact of stigma in psychological and social well-being of people with mental illness by reducing their life chances and social opportunities (Link and Phelan 2001; Vogel et al. 2006).

\section{Internalized Stigma}

CIS-IUL, Instituto Universitário de Lisboa (ISCTE-IUL), Av. das Forças Armadas, 1649-026 Lisboa, Portugal

e-mail: seholiveira@gmail.com

E. G. Pereira - M. Carvalho

Faculdade de Psicologia da Universidade Lusófona de

Humanidades e Tecnologia, Lisboa, Portugal

M. Carvalho

Serviço de Psiquiatria do CHBA, Algarve, Portugal

J. E. Boyd

San Francisco VA Medical Center and University of California/

San Francisco, San Francisco, CA, USA
The stigma of mental illness is often evoked by some signs (e.g. psychiatric symptoms, social skills deficits, physical appearance and labels) that frighten the public (Corrigan and Kleinlein 2005).The perception of being treated with devaluation and rejection, based on the marks or signs associated with a mental illness, may lead to stereotype agreement, self-prejudice and self-discrimination (Watson and River 2005), persisting even after the symptoms have disappeared (Sartorius 2006). Hence, the negative consequences of stigma occur when, once stigmatized, a person 
internalizes these generally-accepted views, endorsing and applying negative stereotypes to oneself.

Internalized stigma may constitute, then, a vicious cycle activated by a sense of being different due to the experience of having a psychiatric disorder, negatively impacting the perceptions, beliefs, emotions (Ritsher and Phelan 2004) and the behavior of the stigmatized. These life experiences can cause hurt, anger, hopelessness and progressive damage to oneself, which can lead to self-devaluation, shame, secrecy (Corrigan 1998), anticipated rejection (Angermeyer et al. 2004), seriously affecting a person's self-esteem (e.g. "being treated as less human because of mental illness, sent me into the darkest depression. Nothing compares with being treated as if one were a freak, unworthy of respect" Murphy 1998, p.185). Nevertheless, this is not a linear process in terms of cause-effect consequences, and as Corrigan and Watson (2002) suggested, low self-esteem versus righteous anger defines a fundamental paradox in self-stigma. As proposed by the situational model of the personal response to stigma (Corrigan and Watson 2002), a person with mental illness may experience diminished self-esteem, act indifferently or display righteous anger, depending on his/her perceived legitimacy of public stigma and the degree of group identification. Whereas individuals who perceive the negative response to be legitimate are more likely to demonstrate diminished self-esteem, those who identify themselves with the stigmatized group but consider stigma to be illegitimate will maintain their self-esteem unharmed. Conversely, people who do not seem to identify with the group will react relatively indifferent to stigma, irrespective of their perceptions of its legitimacy. In this context, and because not everyone with mental illness will internalize stigma (Corrigan et al. 2011), stigma resistance concerns to the individual experience of counteracting the stigma of mental illness, and the capacity to demonstrate resilience and empowerment to fight against social discrimination (Ritsher et al. 2003).

While the importance of evaluating the experience of stigmatization is well recognized, most of the research in this area has been conducted with members of the general public (Rüsch et al. 2010). Less attention has been given to the comprehension of stigma from the point of view of the person with mental illness (Thornicroft et al. 2007). Furthermore, while previous research has mainly focused on stigma with schizophrenia (e.g. Bradshaw and Brekke 1999; Dickerson et al. 2002; Lysaker et al. 2007; Werner et al. 2007; Yanos et al. 2008) fewer studies have addressed the impact of internalized stigma in bipolar disorders or depression (Brohan et al. 2011), as well as other mental disorders (Alonso et al. 2009; Ociskova et al. 2013). In fact, although recognized as necessary (Rüsch et al. 2005; West et al. 2011), research examining the effects of internalized stigma in various diagnostic groups, thus, allowing a better understanding of its variability, remains scarce. This study aimed to adapt and assess the psychometric properties of the Portuguese version of the Internalized Stigma of Mental Illness (ISMI) scale. An additional aim was to explore the variability of the response to stigma experiences among five psychiatric disorders. Improving understanding on the variability of the response to stigma among various mental disorders may be a valuable contribution to guide research and clinical intervention, specifically, allowing the design of programs targeting internalized stigma.

\section{Methods}

Translation and Cultural Adaptation Procedures

This study examined the cultural adaptation of the ISMI scale (Internalized Stigma of Mental Illness, Ritsher et al. 2003) to Portuguese. The procedure was based in the ISPOR (International Society For Pharmacoeconomics and Outcomes Research) Principles of Good Practice for the Cross-Cultural Adaptation Process for Patient-Reported Outcomes Measures, using the steps enumerated below (Wild et al. 2005).

\section{Step 1: Preparation}

Previous approval from the authors of the ISMI scale to develop the cultural adaptation and validation of the Portuguese version, and the permission from the Brazilian author to use the Brazilian Portuguese version were obtained.

The implementation involved the Portuguese research group, independent professionals who carried out the translation and back-translations and revision process and also the participation of the author of the original instrument.

\section{Step 2: First Translation}

The Brazilian Portuguese version was analyzed and the original version translated by an independent professional who was a native speaker of both Portuguese and English.

\section{Step 3: Reconciliation}

The Portuguese translation and the Brazilian version were compared by the research group. Despite specific linguistic expressions and cultural differences that were analysed, the two versions turned out to be very close in terms of conceptual equivalence. 


\section{Step 4: Back Translation}

Two independent bilingual experts delivered back-translations of the Portuguese version in order to test the quality control of the produced version.

\section{Step 5: Back Translation Revision}

The versions were reviewed by an expert panel with broad experience in mental health (a psychiatrist and a clinical psychologist) in order to guarantee the conceptual equivalence of the translation and establish the semantic and cultural adaptation of the measure. Minor discrepancies were analysed and expression changes were integrated into the initial Portuguese version of the ISMI scale.

\section{Step 6: Harmonization}

Harmonization process is taken when an instrument is being adapted simultaneously into different languages and back translations compared in the different target countries, which did not apply to this study.

\section{Step 7: Cognitive Debriefing}

In order to analyse the level of comprehensibility of the translated version, identify and overcome confusion in terms that may cause misinterpretations, and also to test eventual translation alternatives, cognitive debriefing was performed. The Portuguese version of the ISMI scale was pilot tested, after informed consent, with twenty patients with a mental illness, using three response options (1-I dońt understand; 2-I understand more or less; 3-I understand very well). Individual interviews were conducted and all the items were read aloud to enhance the respondents understanding about each item of the questionnaire, as well as to test participants' comprehension level. If the participants reported any doubt, they were encouraged to make recommendations and when necessary, a suggestion was made in order to test his/her interpretation and translation alternatives. The participants were also invited to share their insights on the clarity of the instructions, terms and the contents of items of the scale as well as the usefulness of the scale itself as an instrument to measure internalized stigma.

\section{Step 8: Review of Cognitive Debriefing Results and Finalization}

The debriefing results were reviewed and the modifications suggested by patients were discussed with the author of the original scale, in order to ensure the comprehensibility to participants as well as the accuracy of the concepts underlying the items. The reconciled version was discussed and final reformulations were made.

\section{Step 9: Proofreading}

Minor errors were checked and orthographic revision of the Portuguese final version of the ISMI scale was conducted by the research group as a final quality control step.

\section{Step 10: Final Report}

The Translation and Cultural Adaptation group recommends that a final report should be made in order to guide future adaptations of the same instrument to other cultures. This paper would serve as that report.

Participants

This study included 253 adult psychiatric outpatients (201 women [79.4\%] and 52 men [20.6\%]), recruited from the psychiatry service of a general hospital and a primary care center. After official permission from the ethical committee of the institution and written informed consent from the participants, individual interviews were conducted. The mean age of the sample was $46.69 \quad(S D=12.50$; range $=19-76)$. Inclusion criteria were: (1) adults with a clinical diagnosis according to the Diagnostic and Statistical Manual of Mental Disorders (DSM-IV, American Psychiatric Association 1994); (2) without neurological disorders or severe cognitive impairments or intellectual disabilities; (3) under psychiatric treatment and supervision and medically stabilized. Considering these criteria, individuals were selected and referred by the psychiatrist, with only one patient being excluded due to history of intellectual disability.

The institutional review boards of the general hospital and a primary care center where the research was conducted approved the study, including the ethical considerations.

\section{Measure}

\section{The Internalized Stigma of Mental Illness (ISMI) Scale}

The Internalized Stigma of Mental Illness is a 29-item scale (Ritsher et al. 2003), designed to assess the subjective experience of stigma, composed by five subscales measuring: social withdrawal (six items), reflects avoidance in talking about himself/herself and connecting with others due to feeling the burden of the experience of having a mental illness; stereotype endorsement (seven items) measures the level of agreement with the stereotypes usually attributed to people with mental illnesses; alienation (six items) refers to the subjective experience of not feeling 
like a full member of society; discrimination experience (five items) reports the perception of how individuals feel they tend to be treated by others; and stigma resistance (five reverse-coded items) measures the experience of resisting or not being affected by internalized stigma. The items are rated on a four-point Likert scale (from 1strongly disagree to 4-strongly agree). High scores indicate higher levels of internalized stigma. The internal consistency of the original version was $0.90(\mathrm{~N}=127)$ and the test-retest reliability coefficient was $r=0.92(n=16$, $p<0.05$ ), after a 6 weeks interval. The internal consistency and test-retest reliability for the five subscales were: social withdrawal, $0.80,0.89$; stereotype endorsement, $0.72,0.94$; alienation, $0.79,0.68$; discrimination experience, $0.75,0.89$ and stigma resistance, $0.58,0.80$ (Ritsher et al. 2003).

\section{Data Analysis}

Data was analyzed by using the SPSS software, version 18.0. Descriptive statistics were calculated for the sociodemographic and clinical variables. An exploratory factor analysis, with varimax rotation, was carried out using the following criteria: (1) Kaiser-Meyer-Olkin measure of sampling adequacy (KMO) $>0.60$ and Bartlett's test of sphericity with $p<0.05$; (2) eigenvalue $>1$ in line with the scree plot and the percentage of variance explained; (3) loading variables $>0.40$; (4) substantive meaning of the item in each factor. Internal consistency was calculated by using Cronbach's alpha. Pearson correlations were used to examine the relationships between the total scale and the subscales. To analyze differences between the diagnostic groups, we performed a one-way analysis of variance (ANOVA) and post hoc tests (Tukey test) comparing parwise of the ISMI scale means scores.

\section{Results}

\section{Descriptive Analyses}

The means and standard deviations (SDs) for the five subscales and the total scale were the following: social withdrawal, $2.53(S D=0.66)$; stereotype endorsement $2.44(S D=0.72)$; alienation, $2.85(S D=0.62)$; discrimination experience $2.48(S D=0.61)$; stigma resistance 2.02 $(S D=0.47)$ and total scale $2.53(S D=0.39)$. The midpoint of the range of the responses 1 ("strongly disagree") to 4 ("strongly agree") is 2.5 . The means for the individual items ranged from 1.8 to 3.4 with $S D s$ ranging from 0.57 to 1.06.
Exploratory Factor Analysis

The study of the psychometric properties of the Portuguese version of the ISMI scale followed the original study procedures (Ritsher et al. 2003). The factorial analysis results closely replicated the original version. However, although violence is a key component of stigma, in this version item 2 , "Mentally ill people tend to be violent" had weak loading and communality values. Besides, it sorted into a different factor than in the original version (it sorted in the alienation factor although belonging to the stereotype endorsement factor), suggesting a weak relationship with the other items and lack of substantive meaning of the item in this factor. On this basis, and in order to ensure that the items are fully representative of its factor and also the scale factorial stability, item 2 was excluded from further analysis. The Portuguese version of the ISMI scale is now a 28 -item scale, distributed in a fivedimension solution, explaining $58.49 \%$ of the total variance. The KMO value was 0.833 and Bartlett's test value $p<0.001$, supporting the adequacy of the factor analysis.

Component loadings greater than 0.40 were considered statistically significant, with exception for one item that revealed a loading value slightly below (0.34), but was preserved due to it substantive meaning and contribution to the subscale, and taking into account the sample size (Stevens 1986).

The first factor was composed of eight items assessing social withdrawal (explained variance of $21.87 \%$ ); the second factor, with five items that assess stereotype endorsement (accounted for $18.18 \%$ of the variance); the third factor, with seven items related to alienation (explained $6.49 \%$ of variance); the fourth factor, consisting of five items that refers to the discrimination experience (6.29\% of the explained variance) and the fifth factor, consisting of three items that assess stigma resistance (explained $5.66 \%$ of the total variance).

\section{Reliability}

The internal consistency indices were 0.85 for the total scale. The Cronbach's alpha coefficients for the five subscales were as follows: stereotype endorsement 0.90; discrimination experience 0.80 ; social withdrawal 0.83 ; alienation 0.84 and stigma resistance 0.64 . As in the original study, lower levels of reliability were found in the stigma resistance subscale.

\section{Criterion-related Validity}

In order to analyze the variability in the experience of the internalization of stigma across groups, the means and $S D$ 's ranging scores and reliability were examined. 
The items means ranges and Cronbach's alpha for the five diagnostic groups in the present study were as follows: from 1.79 to 3.44 (SD's range, $0.46-1.25$ ) and 0.83 for the participants with psychotic disorders $(n=43)$; from 1.85 to 3.44 (SD range, 0.53-1.06) and 0.86 for participants with depressive disorders $(\mathrm{n}=117)$; from 1.61 to 3.50 (SD range, 0.54-1.03) and 0.80 for those with bipolar disorders ( $\mathrm{n}=18$ ); from 1.82 to 3.35 (SD range, $0.49-1.18$ ) and 0.72 for participants with anxiety disorders $(n=17)$; from 1.53 to 3.31 (SD range, 0.61-1.03) and 0.89 for participants with personality disorders $(n=58)$, respectively.

Interestingly, for four of the five diagnostic groups included in this study, the item with the highest mean was "People without mental illness could not possibly understand me" $(\mathrm{M}=3.41)$, with exception for the participants with bipolar disorders in which the mean had a higher score in the item "I dońt socialize as much as I used to because my mental illness might make me look or behave [weird]" $(\mathrm{M}=3.61)$. For all the diagnostic groups, two of the four most strongly endorsed items were "People without mental illness could not possibly understand me" (Item means ranged from 3.31 to 3.44 ) and "Having a mental illness has spoiled my life" (Item means ranged from 2.97 to 3.44). As in the original version of the ISMI scale study, considering that 2.5 is the midpoint of the range, the Portuguese participants also revealed high mean scores in the item "I feel out of place in the world because I have a mental illness" (Item means ranged from 2.88 to 3.30), suggesting the cross-cultural nature of the experience of stigma.

With respect to levels of internalized stigma between the diagnostic groups, the post hoc test results demonstrated higher scores for the total scale in participants with bipolar disorders compared to those with psychotic disorders $(p=0.014)$, depressive disorders $(p=0.010)$ and anxiety disorders $(p=0.018)$. Significant differences in the same direction were also found for social withdrawal $(p=0.000)$; stereotype endorsement $(p=0.038)$ and discrimination experience ( $p=0.014)$, with exception for alienation $(p=0.032)$, in which participants with psychotic disorders reported higher levels of stigma. No significant differences were found between diagnostic groups for the resistance subscale $(p>0.05)$.

\section{Correlations}

The intercorrelations between the subscales were found to be significant $(r=0.125, p<0.05)$. As predicted all of the ISMI subscales showed moderate correlations with the total scale, at $p<0.01$ level ( $r=0.410$ to $r=0.669$ ).

\section{Discussion}

The aim of this study was to adapt and assess the psychometric properties of the Portuguese version of the ISMI scale. A further aim was to examine the variability on the internalization of stigma across clinical diagnoses. The Portuguese version is now a 28-item scale with a fivefactor structure, as reported by Ritsher et al. (2003), with one item less than the original. The good internal consistency reliability also suggests that the items are measuring the same construct. This may be attributable to the methodology used, including, the rigorous translation process and individual interviews with all the items read aloud, which may have contributed to enhance understandability by the participants.

The results of this study advance previous research on internalized stigma in two main aspects. First, our findings strengthen the cross-cultural nature of internalized stigma, demonstrating that the Portuguese version of the ISMI scale has adequate psychometric properties, and suggesting that this instrument is appropriate to measure internalized stigma across very distinctive linguistic and cultural countries (Boyd et al. 2014). On the subject of the stigma resistance subscale, this dimension has shown weaker internal consistency, as reported elsewhere (Brohan et al. 2011) and no significant differences were found between diagnostic groups. Further investigation or even the need to explore the stigma resistance dimension as a distinct construct is required (Sibitz et al. 2009). Nevertheless, lower levels of stigma resistance and higher levels of internalized stigma, for almost all of the scale items, were found in the Portuguese sample compared to those obtained by Ritsher el al. (2003).

Second, due to the recognized need to improve understanding regarding the differentiation between various mental disorders (Angermeyer and Matschinger 2003), this study extended the research of the majority of studies on the variability of internalized stigma, as it presents data comparing five diagnostic groups. Our findings may have important practical implications, helping to increase awareness among clinicians regarding the role that diagnosis may play in the internalization of stigma, a serious obstacle to recovery.

Our findings also indicate that internalized stigma is widespread among Portuguese mental health consumers, and that diagnostic labels may affect people with mental illnesses in distinctive ways. For instance, in this study, participants with bipolar disorder reported the highest levels of social withdrawal, stereotype endorsement and discrimination experience. Also, and in line with precedent studies using the ISMI scale, individuals with psychotic disorders reported high levels on the alienation subscale (Ritsher and Phelan 2004; Werner et al. 2007), suggesting that those with psychotic disorders tend to feel that they are not a full member of society (Ritsher et al. 2003). Because social rejection is mostly associated with disorders that are perceived to be high on personal responsibility for the 
illness, dangerousness and rarity (Feldman and Crandall 2007), and since clinical diagnosis exacerbates the stigma of mental illness (Corrigan 2007; Ben-Zeev et al. 2010), internalized stigma may act as a "mirror effect" of social rejection particularly for those with severe forms of mental illness.

Our findings are, therefore, consistent with previous studies evidencing the negative impacts of stigma experiences regarding people with schizophrenia (Brohan et al. 2010; Dickerson et al. 2002; Lysaker et al. 2007; Werner et al. 2007; Yanos et al. 2010) and with bipolar disorders (Perlick et al. 2001; Brohan et al. 2011). Particularly those with severe mental illness may experience rejection in part because they think less of themselves and because of the severity of their illness. Building on the modified labeling theory hypotheses and evidences, (Link et al. 1989) that stresses the permeability of stigma to the cultural environment, once assuming the status of being a "mental patient", some people with a mental illness tend to adopt avoidant coping strategies, such as secrecy and withdrawal from social contacts, which can negatively affect the course of illness and also increase the symptoms (Link et al. 1997).

Some limitations must be considered in this study. First, the cross sectional nature of this study does not allow any conclusions relating to causality. Second, a convenience sample was used in this study. Thus, further data is needed on the performance of the Portuguese version of the ISMI scale in a more representative sample. Also, participants with bipolar disorders and anxiety disorders were both underrepresented in this study since these two subgroups constituted a small proportion of the total sample. Thus, besides exploring internalized stigma in larger clinical samples, future studies should take into account the treatment settings, as well as different stages of the disorder; for example, since symptom onset to recovery.

Despite these limitations, the results of the present study show that the Portuguese version of the ISMI scale has adequate psychometric properties and can be useful to clinicians and researchers to challenge the internalized stigma of mental illness. Finally, findings of this study advance previous research regarding the impact that internalized stigma has on people with different mental disorders suggesting that clinical diagnosis may aggravate the experience of stigma, a central question that should be taken into account as part of anti-stigma programs and selfstigma interventions.

Acknowledgments The authors would like to thank Professor Dr. Erikson Furtado, from the Neurology, Psychiatry and Medical Psychology Department, University of São Paulo, for providing us the Brazilian Version of the ISMI scale. We are grateful for Dr. Vitor Cotovio and Dr. Margarida Cordo collaboration in the back-translation revision. We also thank the participants in this study and the staff from the Department of Psychiatry of the participating Hospital and Primary Care Center.

\section{References}

Alonso, J., Buron, A., Rojas-Farreras, S., de Graaf, R., Haro, J. M., de Girolamo, G., \& Vilagut, G. (2009). Perceived stigma among individuals with common mental disorders. Journal of Affective Disorders, 118, 180-186.

American Psychiatric Association. (1994). Diagnostic and statistical manual of mental disorders (4th ed.). Washington, DC: American Psychiatric Association.

Angermeyer, M. C., Beck, M., Dietrich, S., \& Holzinger, A. (2004). The Stigma of Mental Illness: Patients' Anticipations and Experiences. International Journal of Social Psychiatry, 50, 153-162. doi:10.1177/0020764004043115.

Angermeyer, M. C., \& Matschinger, H. (2003). The stigma of mental illness: Effects of labelling on public attitudes towards people with mental disorder. Acta Psychiatrica Scandinavica, 108, 304-309. doi:10.1034/j.1600-0447.2003.00150.x.

Ben-Zeev, D., Young, M., \& Corrigan, P. W. (2010). DSM-V and the stigma of mental illness. Journal of Mental Health, 19, 318-327. doi:10.3109/09638237.2010.492484.

Boyd, J. E., Adler, E. P., Otilingam, P. G., \& Peters, T. (2014). Internalized Stigma of Mental Illness (ISMI) Scale: A multinational review. Comprehensive Psychiatry, 55, 221-231. doi:10.1016/j.comppsych.2013.06.005.

Bradshaw, W., \& Brekke, J. S. (1999). Subjective experience in schizophrenia: Factors influencing self-esteem, satisfaction with life, and subjective distress. The American Journal of Orthopsychiatry, 69, 254-260.

Brohan, E., Elgie, R., Sartorius, N., \& Thornicroft, G. (2010). Selfstigma, empowerment and perceived discrimination among people with schizophrenia in 14 European countries: The GAMIAN-Europe study. Schizophrenia Research, 122, 232-238.

Brohan, E., Gauci, D., Sartorius, N., \& Thornicroft, G. (2011). Selfstigma, empowerment and perceived discrimination among people with bipolar disorder or depression in 13 European countries: The GAMIAN-Europe study. Journal of Affective Disorders, 129, 56-63. doi:10.1016/j.jad.2010.09.001.

Corrigan, P. W. (1998). The impact of stigma on severe mental illness. Cognitive and Behavioral Practice, 5, 202-222.

Corrigan, P. W. (2000). Mental health stigma as social attribution: Implications for research methods and attitude change. Clinical Psychology Science and Practice, 7, 48-67. doi:10.1093/clipsy. 7.1.48.

Corrigan, P. W. (2007). How clinical diagnosis might exacerbate the stigma of mental illness. Social Work, 52, 31-39.

Corrigan, P. W., Kerr, A., \& Knudsen, L. (2005). The stigma of mental illness: Explanatory models and methods for change. Applied and Preventive Psychology, 11, 179-190.

Corrigan, P. W., \& Kleinlein, P. (2005). The Impact of Mental Illness Stigma. In P. Corrigan (Ed.), On the stigma of mental illness: Practical strategies for research and social change (pp. 11-44). Washington, DC: American Psychological Association.

Corrigan, P. W., Rafacz, J., \& Rüsch, N. (2011). Examining a progressive model of self-stigma and its impact on people with serious mental illness. Psychiatry Research, 189, 339-343. doi:10.1016/j.psychres.2011.05.024.

Corrigan, P. W., \& Watson, A. C. (2002). The paradox of self-stigma and mental illness. Clinical Psychology: Science and Practice, 9, $35-53$.

Dickerson, F. B., Sommerville, J., Origoni, A. E., Ringel, N. B., \& Parente, F. (2002). Experiences of stigma among outpatients with schizophrenia. Schizophrenia Bulletin, 28, 143-155. 
Feldman, D. B., \& Crandall, C. S. (2007). Dimensions of mental illness stigma: What about mental illness causes social rejection? Journal of Social and Clinical Psychology, 26, 137-154. doi:10. 1521/jscp.2007.26.2.137.

Link, B. G., Cullen, F. T., Struening, E., Shrout, P. E., \& Dohrenwend, B. P. (1989). A modified labeling theory approach to mental disorders: An empirical assessment. American Sociological Review, 54, 400-423.

Link, B. G., \& Phelan, J. C. (2001). Conceptualizing stigma. Annual Review of Sociology, 27, 363-385. doi:10.1146/annurev.soc.27. 1.363 .

Link, B. G., Struening, E. L., Rahay, M., Phelan, J. C., \& Nuttbrock, L. (1997). On stigma and its consequences: Evidence from a longitudinal study of men with dual diagnoses of mental illness and substance abuse. Journal of Health and Social Behavior, 38, 177-190.

Link, B. G., Yang, L. H., Phelan, J. C., \& Collins, P. Y. (2004). Measuring mental illness stigma. Schizophrenia Bulletin, 30, $511-541$.

Livingston, J. D., \& Boyd, J. E. (2010). Correlates and consequences of internalized stigma for people living with mental illness: A systematic review and meta-analysis. Social Science and Medicine, 71, 2150-2161. doi:10.1016/j.socscimed.2010.09.030.

Lysaker, P. H., Roe, D., \& Yanos, P. T. (2007). Toward understanding the insight paradox: Internalized stigma moderates the association between insight and social functioning, hope, and selfesteem among people with schizophrenia spectrum disorders. Schizophrenia Bulletin, 33, 192-199. doi:10.1093/schbul/sbl016.

Murphy, M. A. (1998). Rejection, stigma, and hope. Psychiatric Rehabilitation Journal, 22, 185-188. doi:10.1037/h0095248.

Ociskova, M., Prasko, J., \& Sedlackova, Z. (2013). Stigma and selfstigma in patients with anxiety disorders. Activitas Nervosa Superior Rediviva, 55, 12-18.

Perlick, D. A., Rosenheck, R. A., Clarkin, J. F., Sirey, J. A., Salahi, J., Struening, E. L., \& Link, B. G. (2001). Stigma as a barrier to recovery: Adverse effects of perceived stigma on social adaptation of persons diagnosed with bipolar affective disorder. Psychiatric Services, 52, 1627-1632. doi:10.1176/appi.ps.52.12. 1627.

Ritsher, J. B., Otilingam, P. G., \& Grajales, M. (2003). Internalized stigma of mental illness: Psychometric properties of a new measure. Psychiatry Research, 121, 31-49. doi:10.1016/j. psychres.2003.08.008.

Ritsher, J. B., \& Phelan, J. C. (2004). Internalized stigma predicts erosion of morale among psychiatric outpatients. Psychiatry Research, 129, 257-265. doi:10.1016/j.psychres.2004.08.003.

Rüsch, N., Angermeyer, M. C., \& Corrigan, P. W. (2005). Mental illness stigma: Concepts, consequences, and initiatives to reduce stigma. European Psychiatry, 20, 529-539. doi:10.1016/j. eurpsy.2005.04.004.

Rüsch, N., Lieb, K., Bohus, M., \& Corrigan, P. W. (2006). Selfstigma, empowerment, and perceived legitimacy of discrimination among women with mental illness. Psychiatric Services, 57, 399-402. doi:10.1176/appi.ps.57.3.399.
Rüsch, N., Todd, A. R., Bodenhausen, G. V., \& Corrigan, P. W. (2010). Do people with mental illness deserve what they get? Links between meritocratic worldviews and implicit versus explicit stigma. European Archives of Psychiatry and Clinical Neuroscience, 260, 617-625. doi:10.1007/s00406-010-0111-4.

Sartorius, N. (2006). Quality of life and mental disorders: A global perspective. In H. Katschnig, H. Freeman, \& N. Sartorius (Eds.), Quality of life in mental disorders (2nd ed., pp. 321-327). Chichester: Wiley.

Sibitz, I., Unger, A., Woppmann, A., Zidek, T., \& Amering, M. (2009). Stigma resistance in patients with schizophrenia. Schizophrenia Bulletin, 37, 316-323. doi:10.1093/schbul/ sbp048.

Stevens, J. (1986). Applied multivariate statistics for the social sciences. Hillsdale, NJ: Lawrence Erlbaum Associates.

Thornicroft, G., Rose, D., Kassam, A., \& Sartorius, N. (2007). Stigma: Ignorance, prejudice or discrimination? The British Journal of Psychiatry, 190, 192-193. doi:10.1192/bjp.bp.106. 025791.

Vogel, D. L., Wade, N. G., \& Haake, S. (2006). Measuring the selfstigma associated with seeking psychological help. Journal of Counseling Psychology, 53, 325-337. doi:10.1037/0022-0167. 53.3.325.

Watson, A. C., \& Larson, J. E. (2006). Personal responses to disability stigma: From self-stigma to empowerment. Rehabilitation Education, 20, 235-246. doi:10.1891/088970106805065377.

Watson, A. C., \& River, L. P. (2005). A Social-Cognitive model of personal responses to stigma. In P. Corrigan (Ed.), On the stigma of mental illness: Practical strategies for research and social change (pp. 145-164). Washington, DC: American Psychological Association.

Werner, P., Aviv, A., \& Barak, Y. (2007). Self-stigma, self-esteem and age in persons with schizophrenia. International Psychogeriatrics, 20, 174-187. doi:10.1017/S1041610207005340.

West, M. L., Yanos, P. T., Smith, S. M., Roe, D., \& Lysaker, P. H. (2011). Prevalence of internalized stigma among persons with severe mental illness. Stigma Research Action, 1, 3-10. doi:10. 5463/sra.v1i1.9.

Wild, D., Grove, A., Martin, M., Eremenco, S., McElroy, S., VerjeeLorenz, A., \& Erikson, P. (2005). Principles of good practice for the translation and cultural adaptation process for patientreported outcomes (PRO) measures: Report of the ISPOR task force for translation and cultural adaptation. Value in Health, 8, 94-104. doi:10.1111/j.1524-4733.2005.04054.x.

Yanos, P. T., Lysaker, P. H., \& Roe, D. (2010). Internalized stigma as a barrier to improvement in vocational functioning among people with schizophrenia-spectrum disorders. Psychiatry Research, 178, 211-213. doi:10.1016/j.psychres.2010.01.003.

Yanos, P. T., Roe, D., Markus, K., \& Lysaker, P. H. (2008). Pathways between internalized stigma and outcomes related to recovery in schizophrenia spectrum disorders. Psychiatric Services, 59, 1437-1442. 